\title{
THE REVISED INPUT-OUTPUT TABLE TO DETERMINE TOTAL ENERGY CONTENT AND TOTAL GREENHOUSE GAS EMISSION FACTORS IN THAILAND
}

\author{
Pruethsan Sutthichaimethee' ${ }^{1}$, Danupon Ariyasajjakorn' ${ }^{1}$ \\ 1 Faculty of Economics, Chulalongkorn University, Wang Mai, Khet Pathum Wan, Krung Thep Maha Nakhon, \\ Bangkok, Thailand, e-mail: pruethsan@gmail.com, Danupon.A@Chula.ac.th.
}

Received: 2017.09.05

Accepted: 2017.10.01

Published: 2017.11.01

\begin{abstract}
A full energy chain analysis (FENCH) or a life cycle analysis (LCA) is indeed essential in making any decision on both minimal greenhouse gas (GHG) emissions and the energy content in various commodities. In this article, the energy Input-Output Analysis (IOA) approach is investigated to determine the factors for the total greenhouse gas emission and total energy content, and it deems the elimination of the boundary constraints existing in the Process Chain Analysis (PCA) approach to be practical to. This study, aims to identify the factors in embedded energy and embedded greenhouse gas (GHG) total values derived from the total Thai economic sectors of 180 in various commodities productions. The previous outdated IOA is enhanced in the study by revising the elements of sectoral energy consumption in the power sector, which is later found to be influential and significant to all other economic sectors. In addition, the 2005 sectoral energy consumption is used to show individual energy consumption, whereas the 2010 Input-Output (I-O) table, most timely data, is used to show the economic structure. Furthermore, the study uses a report of Thai electric power to revise the data of 2005 fuel mix in the power sector in order to obtain the 2010 and 2015 fuel mix. The reason of such revision is that the changes of fuel mix in the power sector are influential towards the factors in both total energy content and total greenhouse (GHG) emission. Hence, the 2015 electricity-fuel mix is taken to present the above-mentioned factors.
\end{abstract}

Keywords: input-output analysis, full energy chain analysis (FENCH), life cycle analysis, process chain analysis, greenhouse gas emission factor, energy consumption

\section{INTRODUCTION}

A full energy chain analysis (FENCH) also known as a life cycle analysis (LCA) is a very important instrument or approach that comes with many layers of processes to facilitate the selection of a variety of products as a target of minimal greenhouse gas emissions and minimal energy content. The life cycle analysis approach can be called a process chain analysis (PCA), and it is normally encountering boundary constraints. On the other hand, the input-out analysis (IOA) provides an average value that is utilized from past data [Asian Development Bank: ADB 2014, Office of the National Economic and Social Development Board: NESDB 2015, Thailand Development Research Institute: TDRI 2007]. With the presence of boundary truncations in the LCA analysis, the combined PCA and IOA approach, can be a wise method to reduce those truncations. However, the outer boundary layer still exists in the IOA approach. In order to better combine PCA and IOA, an energy IOA analysis is evaluated to identify the factors of total greenhouse gas emis- 
sions and total energy content [Pruethsan 2017, Pruethsan and Danupon 2017, Sutthichaimethee and Sawangdee 2016].

By analyzing IOA under huge isolated economic sector, the deficiency of mean results could be dwindled. This study attempts to determine the factors in embedded energy and embedded greenhouse gas (GHG) total values emitted from the total Thai economic sectors of 180 in various commodities productions by energy IOA method to reduce the gap of PCA boundary. Meanwhile, the old IOA data shall be updated by revising the elements of sectoral energy consumption in big consuming sector within the economy [Barak and Dahooie 2015, Pruethsan et.al 2015, Pruethsan et al 2016, Pruethsan 2016].

Here, many assessments are investigated, but their results are not concurrent as there are changes in the structures of economy and energy consumption. Nevertheless, the energy I-O data for the year of 2005 and 2010 has been finally issued, and they are later used for another research. However, the above-mentioned work keeps the factors unchanged, while the fuel mix in Thai power sector of the year 2010 is, in fact, different from the fuel mix of the year 2005. Besides, the fuel mix of the year 2015 steadily changes from the energy I-O of the year 2005. Thus, the researcher sees that revision of the energy consumption mix in the power sector can offer a big change and better results for the study. The factors of greenhouse gas emissions and energy intensity of the year 2010 and 2015 can be retrieved from the results obtained in this study [Pruethsan and Danupon 2017].

\section{METHODOLOGY}

The vector of sectoral energy consumption is denoted as $f_{k j}$, and it represents an energy amount of kind $\mathrm{k}$ directly consumed by sector $\mathrm{j}$ per $\mathrm{X}$ as a total monetary output of sector $\mathrm{j}(\mathrm{TJ} / \mathrm{million} \mathrm{Baht})$;

$$
f_{k j}=\frac{F_{k j}}{X_{j}}
$$

where $f_{k j}$ is the energy kind $k$ needed as an input for sector $j$ in a common energy unit, $X j$ is the total output of sector $j$ (in a monetary unit).

The equation below further demonstrates $j$ which is the power sector with kind of fuel $k$ consumed by the power sector in year $n$;

$$
\begin{aligned}
& F_{k j}=\frac{\text { Electricity output }}{\eta_{k, \text { avg }}} \\
& F_{k j, n}=\frac{G_{k, n} \cdot(C F)}{\eta_{k, a v g}}
\end{aligned}
$$

Here, $G_{k, n}$ represents a portion of electricity generation as an output by kind of fuel $k(\mathrm{GWh})$, and $C F$ is the conversion factor attempting to transform the GWh into the common energy unit as shown in the above $F_{k j n}$. On the other hand, $\eta_{k, \text { avg }}$ is the average efficiency of electricity generation within the country by $k$ fuel in year $n$ (GWh):

$$
G_{k, n}=S H_{k, n} \cdot G_{\text {total }, n}
$$

Using the above-mentioned equation, $\mathrm{SH}_{k, n}$ is defined to be the electricity generation portion percentage by fuel kind $k$ per total electricity production in year $n$, and $G_{\text {total, } n}$ refers to the total electricity production in year $n(\mathrm{GWh})$. Once the equation (2) and (3) are presented, the substitution of equation (3) with equation (2) will give the following:

$$
F_{k j, n}=\frac{S H_{k, n} \cdot G_{t o t a l, n \cdot}(C F)}{\eta_{k, a v g, n}}
$$

Next, the total output of the power sector (million Baht) in year $n$ is presented below:

$$
X_{j, n}=S_{n} \cdot P_{n}
$$

Here, $P_{n}$ is defined as the price of electricity in year $n(\mathrm{Baht} / \mathrm{kWh})$, and $S_{n}$ is the sale of electricity in total in year $n$. Next is the substitution of equation (4) and equation (5) with equation (1),

$$
f_{k j, n}=\frac{S H_{k, n} \cdot G_{t o t a l, n} \cdot(C F)}{\eta_{k, a v g, n} \cdot S_{n} \cdot P_{n}}
$$

As $S_{n}$ is the total electricity sale in year $\mathrm{n}$, it can be derived from the equation below:

$$
s_{n}=G_{t o t a l, n} \cdot \eta_{g e n, n} \cdot\left(1-T D_{l, n}\right) \cdot\left(1-U_{n}\right)
$$

$S_{n}$ can be found by determining $\eta_{g e n, n}$, which corresponds to the total electricity generation efficiency within the country. On the other hand, $T D_{\text {loss, } n}$ is actually referred to two variables; the percentage of both electricity transmission and distribution loss. In addition, $U_{n}$ here denotes the percentage of self-used electricity in the power sector in year $n$. Therefore, it can be concluded that: 


$$
G_{t o t a l, n}=\frac{S_{n}}{\eta_{g e n, n^{*}}\left(1-T D_{l, n}\right) \cdot\left(1-U_{n}\right)}
$$

Once equation 7 is obtained, it shall be substituted with equation 6 in order to retrieve the following equation 8 , which is as follows:

$$
f_{k j . n}=\frac{S H_{k, n} \cdot(C F)}{\eta_{k, a v g, n} \cdot P_{n} \cdot \eta_{g e n, n} \cdot\left(1-T D_{l, n}\right) \cdot\left(1-U_{n}\right)}
$$

After a revision of the fuel mix factor $\left(M_{f, k}\right)$, it must be in a formula as presented below:

$$
\frac{f_{k j, n}}{f_{k j, b}}=\frac{\frac{S H_{k, n}}{S H_{k, b}}}{\frac{\eta_{k, a v g, n}}{\eta_{k, a v g, b}} \cdot \frac{P_{n}}{P_{b}} \cdot \frac{\eta_{g e n, n}}{\eta_{g e n, b}} \cdot \frac{1-T D_{l, n}}{1-T D_{l, d}} \cdot \frac{U_{n}}{U_{b}}}
$$

Here, the $f_{k j}$ in year $n$ can be derived from the multiplication of $f_{k j}$ in the base year with the factor $M_{f, k}$ to express each element in sectoral energy consumption of each type of fuel $k$ consumed in the base year in the power sector. Once each $f_{k j}$ element in the $\mathbf{F}$ matrix is revised, the sectoral energy intensity matrix or EI and the sectoral greenhouse gas emission factors or EF are calculated, and the obtained findings can now be used to indicate the factors of year $n$. In this study, there are three main substances evaluated with the use of different formulas. With the availability of those formulas, $\mathrm{CO}_{2}$ is assessed by the use of method [Sutthichaimethee and Sawangdee 2016], $\mathrm{CH}_{4}$ is evaluated by following the method [Sutthichaimethee and Sawangdee 2016,TDRI 2007], and lastly $\mathrm{N}_{2} \mathrm{O}$ is analyzed by using the method [Pruethsan 2017]. In addition, the GWP from the method [Zhao 2012, Pruethsan and Danupon Ariyasajjakorn 2017] is used to evaluate greenhouse gas.

\section{RESULTS}

Once the factors of fuel mix in the power sector is revised, it is necessary to identify the changes and deviation of factors in both sectoral energy content and greenhouse gas emission for the year 2010 and 2015 from the year 2005, and those are shown in Table 1. According to the presented data, a revised fuel mix in the year of 2005 to 2010 has an average of $1.82 \%$ lower in energy intensity in the economic sector, while $5.84 \%$ in average is the same effect resulting from the year 2005 to 2015 . On the other hand, the green- house gas emission factors are on average lower by $5.12 \%$ in 2010 . On the other hand, in the year 2015 , it is found to be $14.66 \%$ lower in those factors, on average.

However, some selected sectors, like tin ore, ice, iron, steel, wages and salary sector, have small direct primary energy consumption.. In addition to this, the sectors of ice, tin ore, household, cement, railways, ocean transport, basic industrial chemicals, and iron and steel are also among the sectors contributing to greenhouse gas emissions to the greatest degree. This results from their combustion, and with a consumption of the products with high greenhouse gas content, particularly in the sectors of iron and steel, ice, and household.

According to the obtained analysis results, only a direct change in fuel consumption mix exists in the electricity generation. By investigating the reductions, the yield in direct energy content is reduced by 32.5 toe/million Baht, while $\mathrm{CO}_{2}$ is decreased by 115.85 ton/million Baht. What is more, $\mathrm{CH}_{4}$ declined by 0.0015 ton/million Baht with a reduction of $\mathrm{N}_{2} \mathrm{O}$ by 0.0005 ton $/ \mathrm{mil}$ lion Baht. Table 5 shows that 116.03 ton/million Baht could be reduced in direct greenhouse gas emission, while 0.0011 ton/million Baht is the reduction in $\mathrm{N}_{2} \mathrm{O}$. Additionally, it indicates that 129.83 ton/million Baht is the possible reduction in total GHG emission.

As far as full energy chain is concerned, the fuel mix changes in electricity generation have a large direct impact on the energy content and greenhouse gas emissions, as well as indirectly on other economic sectors as a whole. The study shows that the impacts in total energy content of 36.20 toe/million Baht reduced by the total $\mathrm{CO}_{2}$ of 128.98 ton/million Baht, total $\mathrm{CH}_{4}$ decreased by 0.0031 ton/million Baht, total $\mathrm{N}_{2} \mathrm{O}$ dropped by 0.0011 ton/million Baht reduced, and total greenhouse gas emission reduced by 129.35 ton/million Baht.

\section{CONCLUSION}

To conclude, it was found that the electricity sector has the highest energy content and greenhouse gas emission factors. On the other hand, other sectors still show energy content and greenhouse gas emission factors at high level because some sectors still require a great amount of electricity as their input. The energy content will be 
Table 1. The changes in energy intensity or EI and Greenhouse gas emission or GHG factors

\begin{tabular}{|l|c|c|c|c|c|}
\hline \multicolumn{1}{|c|}{ Increase values } & $\mathrm{El}^{*}$ & $\mathrm{CO}_{2}$ & $\mathrm{CH}_{4}$ & $\mathrm{~N}_{2} \mathrm{O}$ & $\mathrm{GHG}$ \\
\hline Direct & 32.51 & 115.83 & 0.0016 & 0.0005 & 116.05 \\
\hline Electricity & 36.20 & 128.98 & 0.0031 & 0.0011 & 129.35 \\
\hline Pipeline & 2.07 & 7.35 & 0.0001 & 0.0000 & 7.38 \\
\hline Petroleum Refinery & 1.98 & 7.05 & 0.0001 & 0.0000 & 7.07 \\
\hline Ice & 11.93 & 42.50 & 0.0005 & 0.0000 & 42.58 \\
\hline Animal Feed & 3.26 & 11.66 & 0.0002 & 0.0000 & 11.69 \\
\hline Household & 6.91 & 24.63 & 0.0002 & 0.0001 & 24.64 \\
\hline
\end{tabular}

high and remain if the petroleum products are consumed. Though the sectors are not the main emitters of greenhouse gas, they still contribute in high energy content and greenhouse gas as their process of production involves combustion. In the case of production and services in Thailand economy, it can be said that some of the sectors directly contribute in greenhouse gas emissions through their combustion processes, whereas other sectors indirectly emit greenhouse gas due to their consumption in high greenhouse content product and services. Consequently, if one sector with a consumption of either high greenhouse gas content product or high energy content, it will put itself in either high total greenhouse gas emission or high total energy content factor. As far as Thailand power sector is concerned, the structure of fuel is yearly altered, and it becomes very significant to the evaluation of both total greenhouse gas emission and total energy content factors.

\section{Acknowledgements}

This research is supported by Rachadapisek Sompote Fund for Postdoctoral Fellowship, Chulalongkorn University.

\section{REFERENCES}

1. Asian Development Bank (ADB). 2014. Environment, Climate Change, and Disaster Risk Management. Manila. Asian Development Bank.

2. Assaad M., Boné R., Cardot H. 2008. A new boosting algorithm for improved time-series forecasting with recurrent neural networks. Inform Fusion, 9, 41-55.

3. Azadeh A., Asadzadeh S., Saberi M., Nadimi V., Tajvidi A., Sheikalishahi M. 2011. A neuro-fuzzystochastic frontier analysis approach for long-term natural gas consumption forecasting and behavior analysis: the cases of Bahrain, Saudi Arabia, Syria, and UAE. Appl Energy, 88, 3850-9.
4. Azadeh A., Saberi M., Seraj O. 2010. An integrated fuzzy regression algorithm for energy consumption estimation with non-stationary data: a case study of Iran. Energy, 35, 2351-66.

5. Barak S., Dahooie JH., Tichy' T. 2015. Wrapper ANFIS-ICA method to do stock market timing and feature selection on the basis of Japanese Candlestick. Expert Syst Appl, 42, 9221-35.

6. Ciabattoni L., Grisostomi M., Ippoliti G., Longhi S. 2014. Fuzzy logic home energy consumption modeling for residential photovoltaic plant sizing in the new Italian scenario. Energy, 74, 359-67.

7. Chienwattanasook Krisada, Sutthichaimethee Pruethsan. (2012). Trend of Thailand Jewelry Export to the USA Market. International Academy of Business and Economics, 12(3).

8. Dong B., Coa C., Lee S.E. 2015. Applying support vector machines to predict building energy consumption in tropical region. Energy Build, 37, 545-553.

9. Ekonomou L. 2010. Greek long-term energy consumption prediction using artificial neural networks. Energy, 35, 512-7.

10. Hao J., Liu D., Li Z., Chen Z., Kong L. 2012. Power system load forecasting based on fuzzy clustering and gray target theory. Energy Proc, 16, 1852-9.

11. Jovanovic RZ., Sretenovic' AA., Z ivkovic' BD. 2015. Ensemble of various neural networks for prediction of heating energy consumption. Energy Build, 94, 189-99.

12. Lee Y-S., Tong L-I. 2011. Forecasting energy consumption using a grey model improved by incorporating genetic programming. Energy Convers Manage, 52, 147-52.

13. Lee Y-S., Tong L-I. 2012. Forecasting nonlinear time series of energy consumption using a hybrid dynamic model. Appl Energy, 94, 251-6.

14. Leontief W.W. 1986. Input-Output Economics (2nd ed.). New York, Oxford University Press.

15. Mamlook R., Badran O., Abdulhadi E. 2009. A fuzzy inference model for short-term load forecasting. Energy Policy, 37, 1239-48.

16. Office of the National Economic and Social Development Board. 2015. National Income of Thailand. Bangkok: NESDB. 
17. Osorio G., Matias J., Catalão J. 2015. Short-term wind power forecasting using adaptive neurofuzzy inference system combined with evolutionary particle swarm optimization, wavelet transform and mutual information. Renew Energy, 75, 301-7.

18. Pappas SS., Ekonomou L., Karamousantas DC., Chatzarakis G., Katsikas S., Liatsis P. 2008. Electricity demand loads modeling using Auto Regressive Moving Average (ARMA) models. Energy, 33, 1353-60.

19. Pruethsan Sutthichaimethee. (2017). VARIMAX Model to Forecast the emission of Carbon Dioxide from Energy Consumption in Rubber and Petroleum industries sectors in Thailand. Journal of Ecological Engineering, 18 (3), 112-117.

20. Pruethsan Sutthichaimethee, et al. (2015). Environmental problems indicator under environmental modeling toward sustainable development. Global J. Environ. Sci. Manage., 14(1), 325-332.

21. Pruethsan Sutthichaimethee, Wanvicechanee Tanoamchard. (2015). Carrying Capacity Model of Food Manufacturing Sectors for Sustainable Development from using Environmental and Natural Resources of Thailand. Journal of Ecological Engineering, 16(5), 1-8.

22. Pruethsan Sutthichaimethee, et al. (2016). Model of Environmental Problems Priority Arising From the Use of Environmental and Natural Resources in Construction Material Sectors of Thailand. Advanced Engineering Forum, 14, 76-85.

23. Pruethsan Sutthichaimethee. (2016). Modeling Environmental Impact of Machinery Sectors to Promote Sustainable Development of Thailand. , Journal of Ecological Engineering, 17 (1).

24. Pruethsan Sutthichaimethee, Yothin Sawangdee. (2016). Indicator of Environmental Problems of Agricultural Sectors under the Environmental Modeling. Journal of Ecological Engineering, 17 (2).

25. Pruethsan Sutthichaimethee, Danupon Ariyasajja- korn. 2017. Forecasting Model of GHG Emission in Manufacturing Sectors of Thailand. Journal of Ecological Engineering, 18 (1), 18-24.

26. Pruethsan Sutthichaimethee, Danupon Ariyasajjakorn. 2017. Forecasting Energy Consumption in Short-Term and Long-Term Period by using Arimax Model in the Construction and Materials Sector in Thailand. Journal of Ecological Engineering, $18(4), 52-59$.

27. Suganthi L., Iniyan S., Samuel AA. 2015. Applications of fuzzy logic in renewable energy systems a review. Renew Sustain Energy Rev, 48, 585-607.

28. Suganthi L., Samuel AA. 2012. Energy models for demand forecasting-a review. Renew Sustain Energy Rev, 16, 1223-40.

29. Sutthichaimethee Pruethsan, Sawangdee Yothin. (2016). Model of Environmental Impact of Service Sectors to Promote Sustainable Development of Thailand. Ethics Sci Environ Polit, 16(1).

30. Sutthichaimethee Pruethsan and Sawangdee Yothin. (2016). Indicator of Environmental Problems Priority Arising from the use of Environmental and Natural Resources in Machinery Sectors of Thailand. Environmental and Climate Technologies .17(1), 18-29.

31. Thailand Development Research Institute (TDRI). 2007. Prioritizing Environmental Problems with Environmental Costs. Final report prepared the Thailand Health Fund. Bangkok.

32. Xie N-m., Yuan C-q., Yang Y-j. 2015. Forecasting China's energy demand and self sufficiency rate by grey forecasting model and Markov model. Int J Electr Power Energy Syst, 66, 1-8.

33. Yu S., Wei Y-M., Wang K. A. 2012. PSO-GA optimal model to estimate primary energy demand of China. Energy Policy, 42, 329-40.

34. Zhao H., Magoulès F. 2012. A review on the prediction of building energy consumption. Renewable Sustainable Energy Rev, 16, 3586-3592. 